Conference Report

\title{
Oil Impregnated Pressboard Barrier Systems Based on Ester Fluids for an Application in HVDC Insulation Systems
}

\author{
Patrick Rumpelt * and Frank Jenau \\ Institute of High Voltage Engineering, TU Dortmund University, 44227 Dortmund, Germany; \\ frank.jenau@tu-dortmund.de \\ * Correspondence: patrick.rumpelt@tu-dortmund.de; Tel.: +49-0231-755-4473
}

Received: 22 November 2017; Accepted: 13 December 2017; Published: 15 December 2017

\begin{abstract}
Ester-based insulation fluids are being increasingly used in high-voltage insulation systems. The reasons are the advantages in the area of ecological compatibility and resource-saving provision. The intention to use ester-based insulation fluids in high voltage direct current (HVDC) equipment is new. The major challenge in designing the HVDC insulation system is, that the systems do not only experience an alternating voltage, but also a direct voltage Offset. This presents a challenge to predict the electric field distribution. For this purpose, basic investigations are carried out in the form of conductivity investigations for various insulation barrier systems. In addition, a mineral oil serves as a reference oil for estimating existing insights. The results show the influence of the ester-based insulating liquids on the direct current (DC) conductivity for basic arrangements, consisting of pressboard barriers and mixed insulations.
\end{abstract}

Keywords: transformer; alternative insulating oils; HVDC insulating system; DC conductivity; pressboard; Midel ${ }^{\circledR} 7131 ;$ FR3 $^{\circledR}$

\section{Introduction}

The insulation materials used in the HVDC transformers correspond to the insulation materials in the conventionally used transformers. Mainly mineral oil-based insulating oils are used. They have very good electrical and dielectric properties, as well as good thermal conductivity. By the addition of additives, excellent aging resistance can be ensured. However, nowadays, the mineral oil, based on its production and environmental compatibility, no longer fits into ever-increasing ecological consciousness. Here, insulating ester-based oils, which have a better environmental compatibility, are biodegradable and consist of renewable raw materials. The synthetic and natural ester fluids are already used in conventional transformers [1,2], and will contribute to make energy transfer more sustainable by means of HVDC technology.

When using ester-based insulating oils, attention is paid to two liquids. Midel ${ }^{\circledR} 7131$ insulating oil from M\&I Materials ${ }^{\circledR}$ is a synthetic ester liquid, and it has already been successfully used in distribution transformers. Envirotemp ${ }^{\circledR}$ FR3 ${ }^{\circledR}$ from Cargill ${ }^{\circledR}$ is to be mentioned as vegetable insulating oil and has already proven its operational capability in conventional transformers. A good example is the world's first exclusively with vegetable oil-powered transformer in the $420 \mathrm{kV}$ range, which has been in operation since the beginning of 2014 in the Bruchsal region of Baden-Württemberg [3].

The state of the art and further developments in this area show that the use of transformers with vegetable insulating oils is increasing worldwide and first HVDC demonstrators are being built, as shown in Figure 1 [4-6]. 


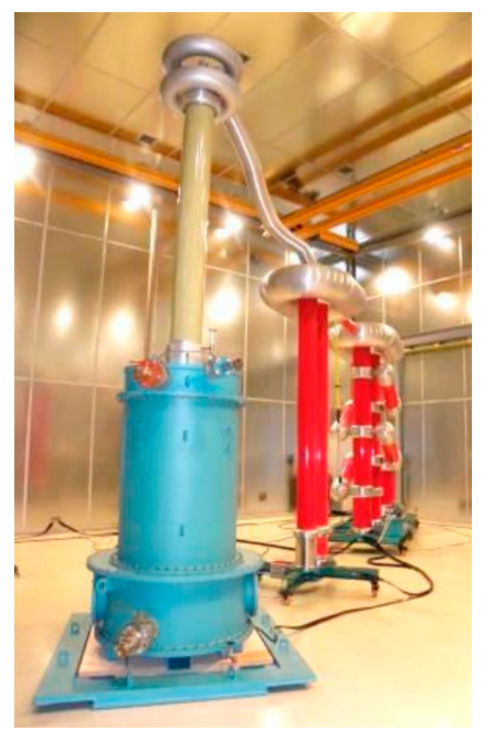

Figure 1. Ester filled HVDC demonstrator in the electrical research Laboratory at Siemens Transformers in Nürnberg, Germany [6].

The major challenge in designing the HVDC insulation system is that the systems do not only experience an alternating voltage, but also a direct voltage Offset. This presents a challenge to predict the electric field distribution. Under DC stress, the conductivity is the determining factor. Although studies have already been carried out $[7,8]$ in this field, further measurements are necessary to understand the behaviour of individual components in the insulation system. The study presented here contributes to the comprehension of oil impregnated pressboard insulation based on ester fluids. For the impregnation of the insulation barrier system, the synthetic insulating oil Midel ${ }^{\circledR} 7131$ and the natural insulation oil FR3 ${ }^{\circledR}$ are used and compared with mineral oil Nytro ${ }^{\circledR}$ Lyra X. For this purpose, attention is first directed to the fabrication and composition of the various liquids, after this, the test vessel with the electrode arrangement will be presented. In order to obtain reproducible results, the pretreatment of the insulating liquids is also explained. The evaluation and comparison of the DC conductivity of three different Basic arrangement insulation barrier systems under laboratory conditions is carried out subsequently.

\section{Fabrication and Composition of Insulation Liquids}

The insulating fluids are fundamentally different in the production, as well as in the composition. The different components of the insulating fluids are the basis for their characteristics and their behaviour under DC voltage application.

\subsection{Mineral Oil}

Crude oil has originated in the earth's crust from the remains of living creatures. Mineral oil is extracted from crude oil by distillation and is processed by various refining processes. The removal of impurities is particularly important. This takes place for example by refining with sulfuric acid, as a result of which impurities are precipitated in the form of acidic sludge [9]. The essential components of mineral oil are shown in Table 1.

Table 1. Ingredients of mineral oil [10].

\begin{tabular}{cc}
\hline Napthene & $30-60 \%$ \\
Paraffin & $40-60 \%$ \\
Aromatic hydrocarbons & $5-20 \%$ \\
Olefine & approx. $1 \%$ \\
\hline
\end{tabular}


Paraffins are open-chain saturated alkanes. They are reactive and ensure that the oil maintains its viscosity even at low temperatures. Moreover, paraffins have good chemical and dielectric properties (e.g., high oxidation stability). However, an exclusively paraffin-based mineral oil is not used because the melting point is too high [9]. Naphthenes belong to the group of alkanes and are referred as cycloalkanes. These are ring-shaped saturated molecules from hydrocarbon compounds. Due to the absence of double bonds and the closed ring structures, these compounds are also chemically stable (reactive), but are less stable than paraffins because the ring structures can be broken by certain chemical reactions [9]. Aromatics, also called benzene, belong to the group of arene. They are distinguished by delocalized double bonds. These molecules are reactive and chemically vulnerable. They are nevertheless used in insulating oils, since they increase the gas resistance of the oil by the addition of hydrogen [11]. Olefins belong to the group of alkenes and are characterized by double bonds between carbon atoms. They increase the aging of the insulating oil and are therefore an undesirable component [11,12]. Nytro ${ }^{\circledR}$ Lyra X from Nynas is a naphthene-based mineral oil.

\subsection{Natural Insulating Oil}

The oil for the production of FR $3^{\circledR}$ is obtained from plant seeds. Soft seeds, such as rapeseed, are squeezed out by means of hydraulic pressure. Hard seeds, e.g., Soybeans, are ground and the oil is extracted using a solvent. Subsequently, the oil is treated to remove polar components and to make the oil odorless. In the final step, additives are added to the oil, which improve the properties of the oil (e.g., melting point, oxidation stability) [13].

FR3 ${ }^{\circledR}$ consists of more than $98 \%$ vegetable oil and approx. $2 \%$ additives. By a California Environmental Protection Agency, the vegetable oil is divided into the following components, shown in Table 2 [14].

Table 2. Ingredients of natural insulation oil [14].

\begin{tabular}{ccc}
\hline \multirow{2}{*}{ Polyunsaturated fatty acids } & Linoleic acid & $52.4 \%$ \\
& Linolenic acid & $7.6 \%$ \\
\hline \multirow{2}{*}{ Monounsaturated fatty acids } & Oleic acid & $23.4 \%$ \\
& Stearic acid & $4.3 \%$ \\
\hline Saturated Fatty Acids & Palmitic acid & $10.6 \%$ \\
\hline
\end{tabular}

To a large extent $(>50 \%)$ FR $3{ }^{\circledR}$ consists of linoleic acid. Due to its double bonds between carbon atoms, this is sensitive to oxidation. The proportion of the generally oxidation-sensitive unsaturated fatty acids $(>75 \%)$ is need for a low pour point. The addition of linoleic acid makes it possible, for example, to significantly reduce the pour point, so that FR ${ }^{\circledR}$ is also a liquid insulating material at low ambient temperatures [13]. For example, an insulating oil consisting exclusively of the oxidation-resistant tripalmitin would be solid at room temperature. The molecular structure differs significantly from mineral oil. FR ${ }^{\circledR}$ consists of long-chain hydrocarbons having 14 to 22 carbon atoms and has several double bonds. Mineral oil is characterized by a predominantly annular structure with considerably fewer double bonds. The main advantages of FR ${ }^{\circledR}$ against mineral oil are the high flame point of $255^{\circ} \mathrm{C}$ and environmental compatibility, FR3 ${ }^{\circledR}$ is biodegradable $[14,15]$. Moreover, the solubility in water of natural esters, such as FR $3^{\circledR}$, is significantly higher than that of mineral oil [14,15]. In the course of the life of a transformer, the degree of polymerization of the paper drops, whereby water is released. As long as the water in the oil can be dissolved, the breakdown strength is only slightly reduced. Only when the saturation concentration is exceeded and the water appears as an emulsion does the breakdown strength rapidly decrease. The higher water solubility thus results in an increased resistance to aging/a longer service life of the insulating oil. The high oxidation susceptibility partly compensates for the increased aging resistance. When oxygen and heat are present, $\mathrm{OH}$ groups are first formed. Subsequently, the hydrogen dissolves and cross-links occur between molecules [16]. This was confirmed in [16] by measurements on various natural oils. 
The oxidation also leads to markedly increased dielectric losses. Due to the fact that the mechanisms that cause dielectric losses usually also cause an increase in conductivity, and since the weakly bound hydrogen atom can easily form an ion in $\mathrm{OH}$ groups, it can be assumed that the oxidation also leads to a rise in conductivity. In addition, the viscosity of the oil is raised by the cross-links, which degrades its cooling properties [16]. The high oxidation susceptibility leads to the fact that when using FR $3{ }^{\circledR}$ it is essential to avoid contact with the air.

\subsection{Synthetic Insulating Oil}

Synthetic esters such as Midel ${ }^{\circledR} 7131$ are not based on naturally occurring esters, like FR3 ${ }^{\circledR}$, it is produced by synthesis. An acid reacts with an alcohol and forms as reaction product an ester with elimination of water. This process is referred to as esterification.

Midel ${ }^{\circledR} 7131$ is an organic ester, known as pentaerythritol tetraester. Due to the complete esterification of the molecules of the alcohol, Midel ${ }^{\circledR} 7131$ has good electrical and chemical properties. It is particularly resistant to hydrolysis, a reverse reaction to esterification: splitting an ester into an alcohol and an acid.

The basic molecular structure of Midel $^{\circledR} 7131$ is similar to the fatty acid residues of FR $3^{\circledR}$. Therefore, it can be assumed that the molecules of Midel ${ }^{\circledR} 7131$ are also significantly larger in comparison to mineral oil. However, since significantly fewer double bonds are present in Midel ${ }^{\circledR} 7131$, the oxidation sensitivity is significantly lower than for FR $3^{\circledR}[17]$. Similar to FR3 ${ }^{\circledR}$, Midel ${ }^{\circledR} 7131$ is characterized by a much higher water saturation and a higher flame point when compared to mineral oil [18].

\section{Test Vessel and Preparation}

A specially developed test vessel was produced for the investigation of DC conductivity. The test vessel in Figure 2 includes a guard ring that is incorporated into a tube glass. Three heating cartridges are also inserted into the tube glass. With these cartridges, a heating of the insulating liquid and the barrier system to a desired temperature profile is achieved.

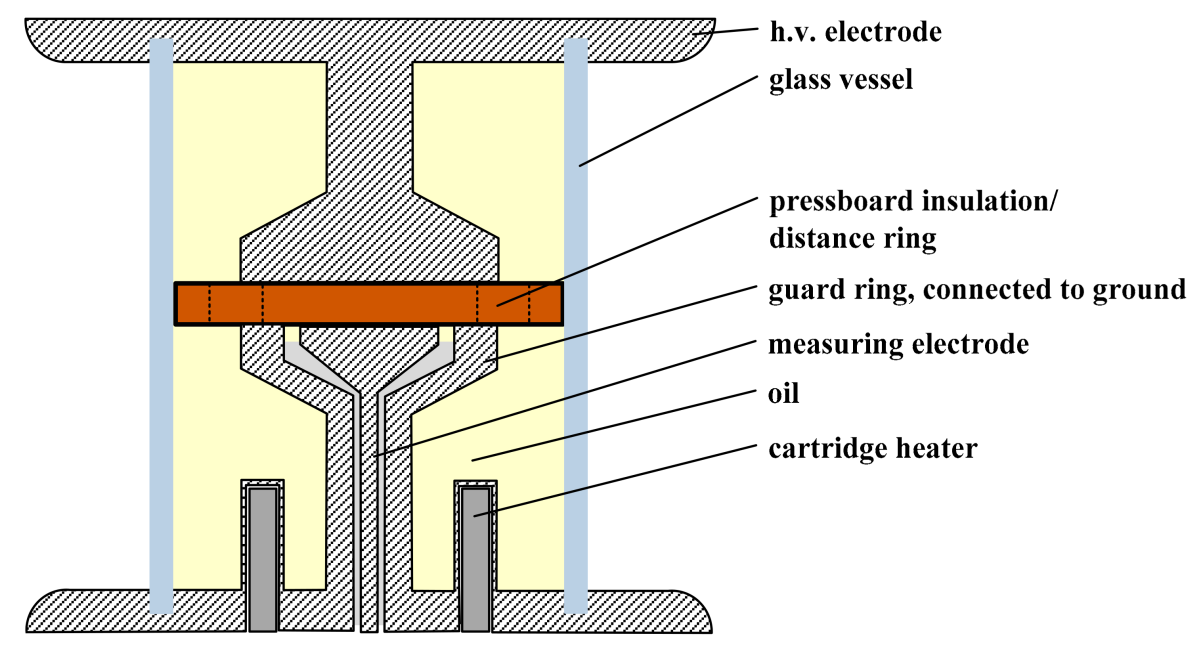

Figure 2. Schematic cross-sectional view of test vessel, pristine pressboard.

The design of the measuring electrode corresponds to the Cigre recommendation by [8]. The implemented pressboard barrier is designed in such a way that it is either a pure $2 \mathrm{~mm}$ oil gap or a $2 \mathrm{~mm}$ pure pressboard barrier. The diameter of the pressboard is equal to the diameter of the tube glass, thus preventing the barriers from slipping. In addition, holes are inserted to the outside, so that an oil curl is ensured. The combination of several kinds of barriers allows for the reproduction of any oil-pressboard insulation section. The object of investigation here is the basic arrangement: pure 
oil gap, pure pressboard, and the combination of oil and pressboard. In each way, the oil gap is located in an enclosed test volume, so that external influences are minimized [19].

The comparability of the measurements is given by the fact that the oil and barrier system is degassed and dehumidified for three days in an oven at $80{ }^{\circ} \mathrm{C}$ under vacuum. For the heating of the insulating oil and the inserted pressboard insulation, a time of $24 \mathrm{~h}$ is chosen and kept constant.

\section{PDC Measurement}

For the polarization and depolarization current measurement (PDC), the investigated arrangements of the isolation barrier system are pre-conditioned with the following voltage curve over time.

The voltage application in Figure 3 shows, before the technical measurement of the dc conductivity (see M1) is made, the pure oil gap and the oil pressboard barrier system, in contrast to the pristine pressboard barrier system, undergoes conditioning in both polarities (see C1, C2). It has been shown that, when measuring pure oil gaps, initially, the charge carriers are distributed freely in the volume and are subjected to a disordered heat movement. An application of voltage causes to the charge carriers to drift toward the electrodes and accumulate there as space charges [5]. Due to the random distribution and the different distances to the electrodes, this results in a turbulent measured current profile that is affected by outliers. In order to counteract this, a prior voltage conditioning is provided for the arrangement with additional oil gap. This ensures that a defined charge carrier distribution prevails in the oil gap and the current can be recorded without any outlier. For the pure pressboard arrangement, the voltage conditioning can be omitted. The reason for this is that the drift processes play a minor role in the pressboard and the polarization effects prevail. This can be exploited, for example, to shorten measurement times. As a consequence of the conditioning, the test vessel is subjected to both polarities. The voltage level is at least the level of the subsequent measurement. The duration is twice the measurement time of the technical measurement. The measurement phase "Depol" is performed after the measuring phase "M1". In this measuring phase, the test vessel is short-circuited over a defined $11 \mathrm{M} \Omega$ resistor and the depolarization current is recorded for six hours. The measurement phase "Depol" of the pure oil gap was dispensed. It has been found that a $2 \mathrm{~mm}$ gap does not have any significant charge carrier storage for the used insulating liquids. Charge carrier storage, however, cannot be ruled out in the case of larger oil gaps, oil sections, or larger oil volumes, and is a current object of investigation.
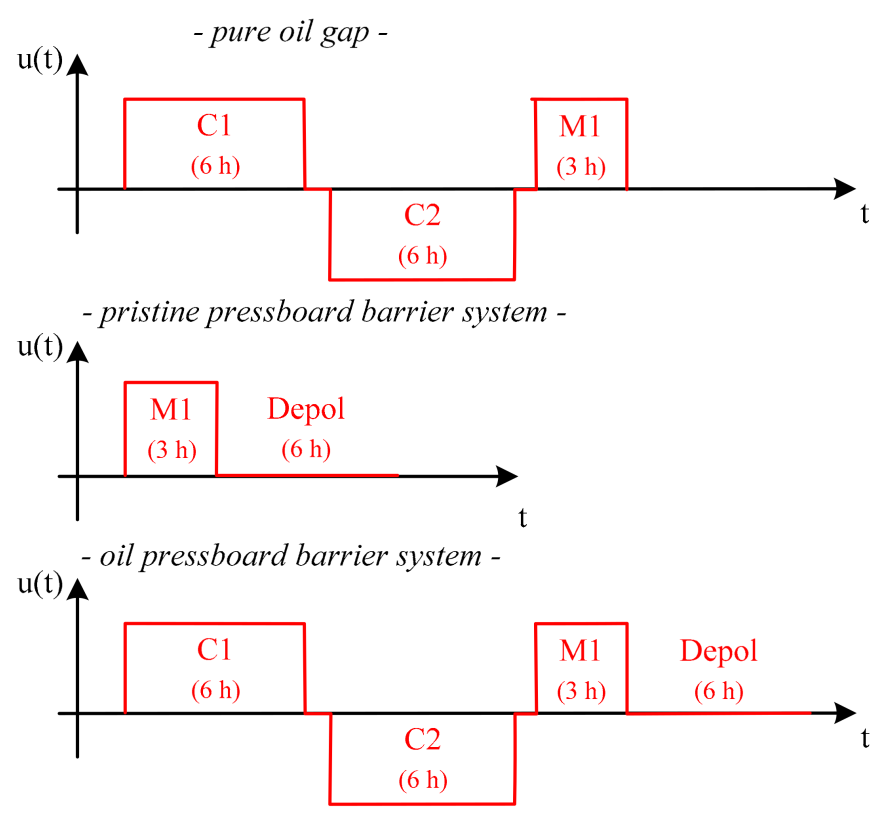

Figure 3. Voltage application for various barrier system arrangements. 
The voltage level during the conditioning, as well as during the subsequent measurement, is $16 \mathrm{kV}$ for both of the arrangements. In addition, the investigations are carried out at a temperature of $50{ }^{\circ} \mathrm{C}$. The elevated temperature was chosen because it can be assumed that stationary end values are reached. The current measurement is performed by using a Keithley 6517B.

\section{Pure Oil Gap}

The evaluation of the pure $2 \mathrm{~mm}$ oil gap in Figure 4 point out that the conductivity of the ester fluids differs by two orders of magnitude from the mineral oil. Furthermore, it can be seen that the apparently steady state occurs earlier in the case of the ester fluids. Similar results on the conductivity of ester fluids relative to mineral oil have already been published in [4].

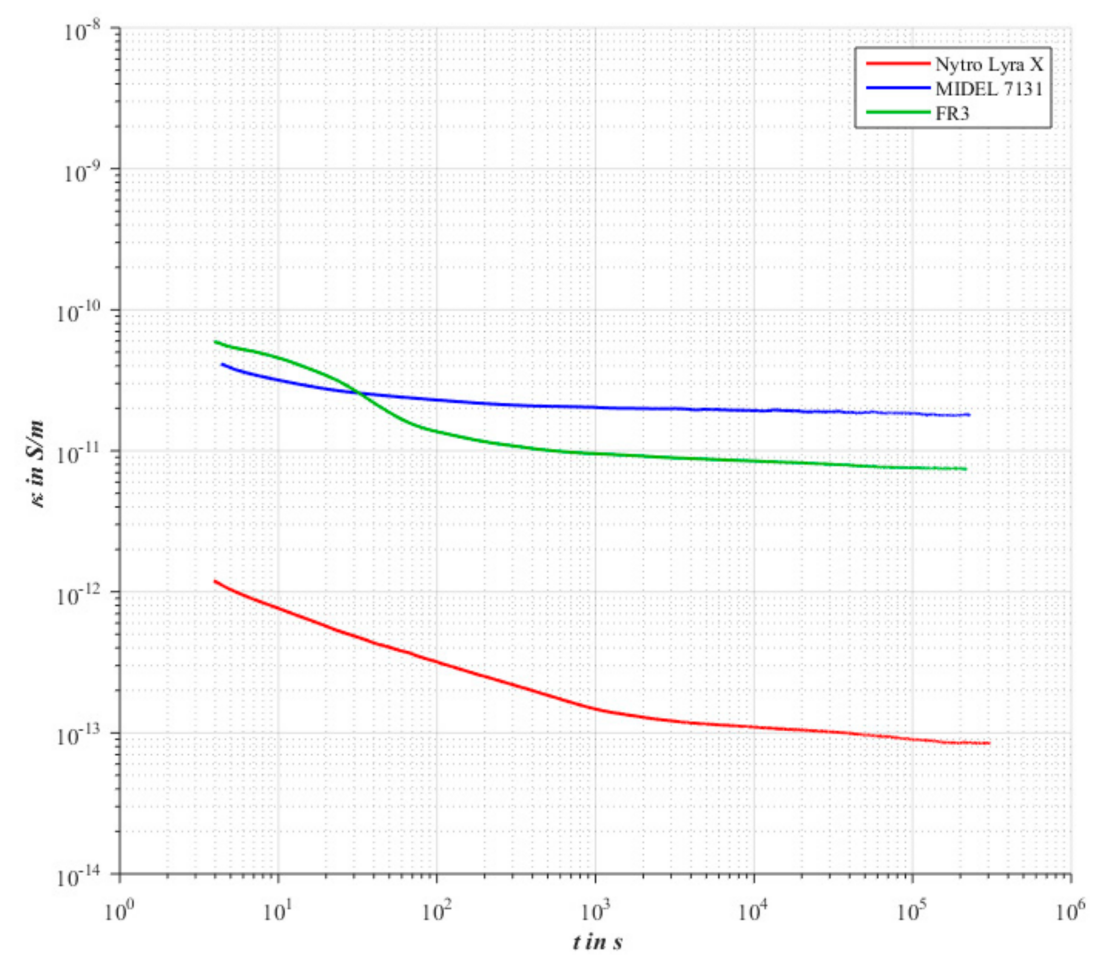

Figure 4. Pure oil gap [20].

The reason for the higher conductivity of the ester liquids is to be assumed in the charge carrier density. With regard to the intrinsic charge carriers, two mechanisms can be found that cause the increased conductivity to be highly probable.

The permittivity for natural and synthetic esters is in the range of three and for mineral oil in the range of two [5,21]. As a result, the Bjerrum length is reduced in esters, which makes electrolytic dissociation more likely. The Bjerrum length is the distance at which the electrostatic energy of two charges becomes comparable to the thermal energy, and is antiproportional to the permittivity. Only after overcoming the Bjerrum length that electrostatic attraction is small enough, permanent dissociation occurs.

The measured fluids possess a permittivity of 2.2 for the mineral oil and 3.2 for the ester fluids. The dielectric constant describes the polarity of a substance. The more inhomogeneous the charge distribution within a molecule, the greater the polarity of the molecule. The differences in the dielectric constant can be explained by means of the electronegativity. This is a measure of the ability of an atom in chemical bonds to attract electrons. Mineral oil consists mainly of carbon and hydrogen, the electronegativity of which is 2.5 and 2.2, respectively, according to the Allred-Rochow scale, and is therefore close to each other. Accordingly, mineral oil is weakly polar. The esters also have small amounts of oxygen and double bonds. According to the Allred-Rochow scale, oxygen has a very high 
electronegativity at 3.5. As a result, the charge distribution is more inhomogeneous, thereby making the dielectric coefficient greater and electrolytic dissociation more likely due to the reduced Bjerrum length.

In addition, it should be noted that separation of thermally generated ion pairs is also more likely due to the different molecular structure in the ester fluids. As shown in the introduction, the molecular structures of the different insulating liquids were compared. It has been shown that the molecules of the ester fluids are significantly larger/longer-chained than the molecules of the mineral oil. According to [22], oblong molecules are required to separate the thermally generated ion pairs. These are available in alternative insulating liquids in higher number.

Another possible cause of the higher conductivity of alternative insulating liquids is the higher absolute water content. In the case of the investigated insulating liquids, the absolute water content of the mineral oil is, on average, $6 \mathrm{ppm}$, and the ester liquids, on average, between $33 \mathrm{ppm}$ and $34 \mathrm{ppm}$. It should be noted that the electrolytic conductivity of water is significantly higher. In addition, the occurrence of other conduction mechanisms (see Grotthus mechanism) leads to higher conductivities. In [21], it was shown that the conductivity and the permittivity increase with increasing water content. Furthermore, the results of [21] suggest that the water in clusters occurs in Midel ${ }^{\circledR} 7131$, which means that the water molecules have contact with each other. Consequently, the electrolytic dissociation in the dissolved water also plays a role and leads to an increase in conductivity when compared to mineral oil, which has lower absolute water content by one to two orders of magnitude [22,23]. In the water clusters the electrolytic dissociation is much more pronounced than in the insulating oil, because water with a permittivity of 81 is much more polar. As a result, more electrolytes dissociate and consequently more charge carriers are available.

\section{Pristine Pressboard Barrier System}

The evaluation of a pristine pressboard barrier impregnated with Nytro ${ }^{\circledR}$ Lyra X shows in Figure 5 the known behavior according to [24,25]. In contrast to a pure oil gap, a pronounced polarization behavior can be observed. It turns out that the insulating material is fully polarized and charged after three hours, resulting in a current that is determined only by the conductivity. The conductivity determined after three hours is $399 \mathrm{fS} / \mathrm{m}$.

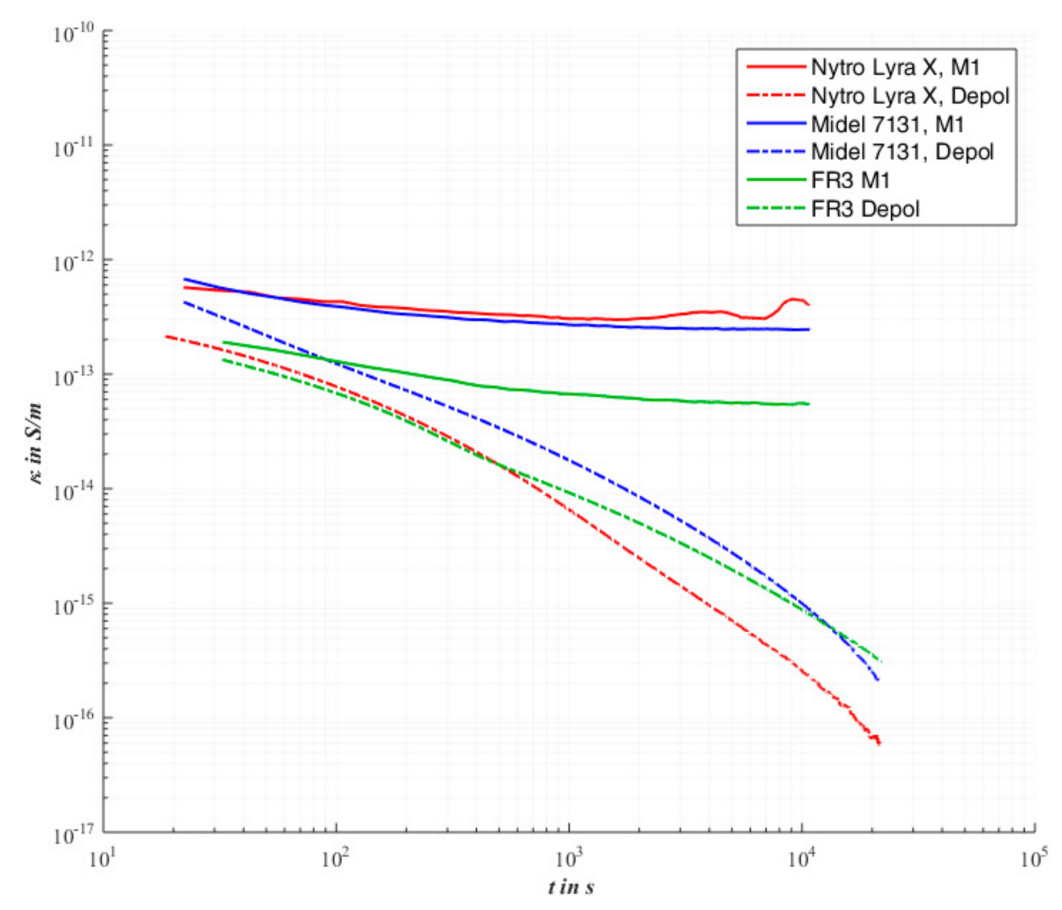

Figure 5. Pristine pressboard barrier system [26]. 
If the M1 measurement is carried out with the same arrangement, which is impregnated with the synthetic insulating oil Midel ${ }^{\circledR} 7131$ in Figure 5, it is found that the curve showing the conductivity assumes a similar curve, like the mineral oil. An apparent steady state value after three hours is reached at $246 \mathrm{fS} / \mathrm{m}$. The depolarization process in Figure 5 shows that the polarization effect is not completed after six hours. The deviation from the value of mineral oil is about a factor of ten.

The PDC measurement with the natural ester clarifies in Figure 5 the smallest stationary final value of all three impregnated pressboard barriers, $54.5 \mathrm{fS} / \mathrm{m}$. Although the values of FR3 ${ }^{\circledR}$ are smaller than the behaviour that is observed for Midel ${ }^{\circledR} 7131$ and Nytro ${ }^{\circledR}$ Lyra X, the basic trend is the same. The depolarization process is also not yet completed, and, like Mide ${ }^{\circledR} 7131$, has a deviation of about a factor of ten from the mineral oil.

The investigations on the pristine pressboard arrangement show that the differences in conductivity between the mineral oil and the ester fluids in a pure oil gap are compensated by the pressboard. Similar statements with various mineral oils have already been made in [25], stating that the oil type has negligible influence on the overall conductivity. The statement from [25] can thus be extended to the oil type ester fluids.

\section{Oil Pressboard Barrier System}

For the subsequent measurements an oil pressboard barrier system is inserted between the electrodes. This insulation system consists of a $2 \mathrm{~mm}$ thick oil gap, as well as a $2 \mathrm{~mm}$ thick pressboard plate. The evaluation of the insulations system, when using mineral oil Nytro ${ }^{\circledR}$ Lyra X in Figure 6, indicate after the polarization that a stationary conductivity of $100 \mathrm{fS} / \mathrm{m}$ is reached. In addition, a clear depolarization process can be observed, which reaches the resolution limit of the measuring instrument after six hours. Furthermore, it is striking that the measured steady state value is close to the final conductivity of the pure pressboard arrangement.

The appraisement of the polarization and depolarization using the synthetic ester fluid in Figure 6 results in a nearly identical curve. The stationary end value is about $200 \mathrm{fS} / \mathrm{m}$. Unlike the mineral oil, the depolarization process has not yet completely subsided. It can be seen that the depolarization has reached an order of magnitude of $10^{-15} \mathrm{~S} / \mathrm{m}$ after six hours, and is not yet completely submerged. When comparing the results with the pure pressboard arrangement in Figure 5, it is also apparent that a further oil gap of $2 \mathrm{~mm}$ has no great influence on the total conductivity.

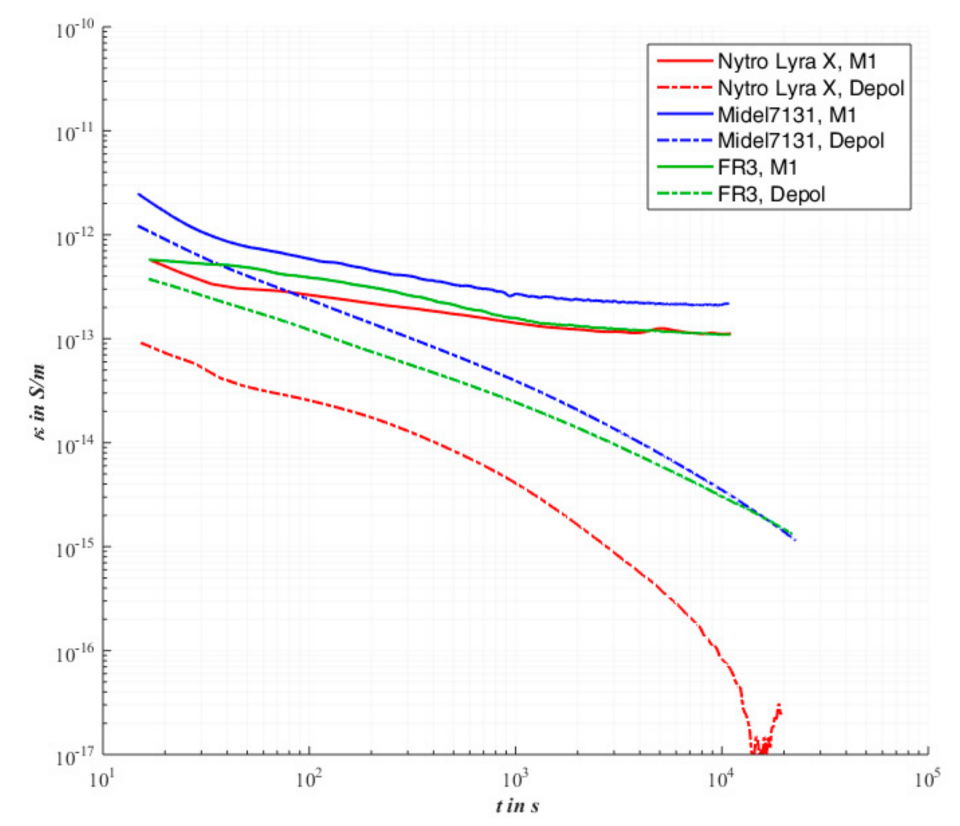

Figure 6. Oil pressboard barrier system [26]. 
If the measurement is carried out under the same conditions with the natural insulating oil, see also Figure 6, a nearly identical polarization process is obtained in comparison to the mineral oil. The final steady state conductivity after three hours is also about $100 \mathrm{fS} / \mathrm{m}$. The naturel insulating oil also has an unfinished depolarization process. This behavior is similar to Midel ${ }^{\circledR} 7131$, in the order of $10^{-15} \mathrm{~S} / \mathrm{m}$. The comparison to the arrangement pure pressboard in Figure 5 hardly shows any deviations in the total conductivity.

The evaluation of the oil pressboard barrier system assembly using mineral oil and ester fluids also shows an equalizing of the total conductivity, and only a slight infiltration of a further oil gap when compared to the arrangement of pure pressboard barrier system. It appears that another oil gap on the total conductivity has no major influence. Furthermore, it is striking that the depolarization process, with the use of a pressboard barrier, requires a considerably longer time for the ester fluids than when using the mineral oil.

\section{Conclusions and Outlook}

The investigations presented oil impregnated pressboard barrier systems that are based on ester fluids. The difference in conductivities for a pure oil gap between the ester fluids and the mineral oil is shown. In connection with the chemical composition of the liquids, different conduction processes are derived, which explains the increased conductivity.

Furthermore, it is found that the strongly varying distinction of the oil conductivities in use with a pure impregnated pressboard is no longer visible. The pressboard dictates the conductivity, the influence of the oils dissolves. Thus, the statement, which has been limited to the conductivity of pure pressboard at various mineral oils [25], can be extended to the oil type ester fluids.

Measurements of arrangements with an oil gap and a pressboard barrier show that the final values align to the values of the pristine pressboard arrangement and the influence of an additional oil gap in the region of a first polarization is not visible in the conductivity. On the other hand, the subsequent measurement of the depolarization current shows a clear difference in the decay behavior. This indicates that by polarity reversal higher conductivity gradients will expected. These findings will be reflected in subsequent voltage reversal investigations.

Continuing investigations will modify the existing arrangement in the following way, that more complex insulation barrier systems will be implemented, which allow for several layers in different thicknesses. In addition, investigations are being undertaken that describe the charge carrier processes in each insulating material more precisely, so as to build up a simulative replica of the processes that is able to predict electrical field conditions in the insulating system.

Acknowledgments: We acknowledge financial support by Deutsche Forschungsgemeinschaft and Technische Universität Dortmund/TU Dortmund Technical University within the funding programme Open Access Publishing.

Author Contributions: Patrick Rumpelt conceived, designed and performed the experiments. The manuscript was written by Patrick Rumpelt and Frank Jenau. All authors have given approval to the final version of the manuscript.

Conflicts of Interest: The authors declare no conflict of interest.

\section{References}

1. Fritsche, R.; Pukel, G.J. Large Power Transformers using alternative liquids-Experience in the range of $420 \mathrm{kV}$ transmission level. In Proceedings of the CIGRÉ Session, Paris, France, 21-26 August 2016.

2. Bae, B.; Kim, S.E. Design of $154 \mathrm{kV}$ power transformer using natural ester oil. In Proceedings of the CIGRÉ Session, Paris, France, 21-26 August 2016.

3. Energie Spektrum. Strom Grün Gewandelt Technik; Henrich Publikationen GmbH: Gilching Germany, 2014.

4. Fritsche, R.; Loppach, K.; Trautmann, F. Transformers for High Voltage Direct Current Transmission-Challenge, Technology and Development; VDE-Hochspannungstechnik: Berlin, Germany, 2016.

5. Martin, R. Experiences in Service with New Insulating Liquids. Available online: http://techcon.asia/ assets/Uploads/CIGRE-A2-35-New-Experiences-in-Service-with-New-Insulating-Liquids.pdf (accessed on 14 December 2017). 
6. Information Flyer. Siemens Innovates: Esters in HVDC Transformers, Peak in Our Electrical Research Laboratory; Siemens Transformers: Nuremberg, Germany, 2016.

7. Schober, F. Electrical Conductivity of Pressboard as a Diagnostic Quantity for HVDC Equipment; VDE Verlag GmbH: Berlin, Germany, 2014.

8. Küchler, A. HVDC Transformer Insulation: Oil Cunductivity; CIGRE Publication: Paris, France, 2016.

9. Lücking, H.W. Energiekabeltechnik; Vieweg+Teubner Verlag: Wiesbaden, Germany, 1981.

10. Beyer, M.; Boeck, W.; Möller, K.U.; Zaengl, W. Hochspannungstechnik. Theoretische und Praktische Grundlagen; Springer: Berlin/Heidelberg, Germany, 1992.

11. Küchler, A. Hochspannungstechnik: Grundlagen, Technologie, Anwendungen, 3rd ed.; Springer: Berlin/Heidelberg, Germany, 2009.

12. Latscha, H.P.; Kazmaier, U.; Klein, H. Organische Chemie: Chemie-Basiswissen II, 7th ed.; Springer: Berlin/Heidelberg, Germany, 2016.

13. Lewand, L.R. Natural Ester Dielectric Liquids. Available online: http://www.netaworld.org/sites/default/ files/public/neta-journals/ChemPerWtr04.pdf (accessed on 14 December 2017).

14. California Environmental Protection Agency. Environmental Technology Verification Report: Cooper Power Systems Envirotemp ${ }^{\circledR}$ FR3 ${ }^{\mathrm{TM}}$ Vegetable Oil-Based Insulating Dielectric Fluid; National Service Center for Environmental Publications: Washington, DC, USA, 2002.

15. Envirotemp. Material Safety Data Sheet_FR3. Available online: https://www.portvancouver.com/wpcontent/uploads/2017/01/G-FR3-Material-Safety-Data-Sheet.pdf (accessed on 14 December 2017).

16. Hosier, I.L.; Guushaa, A.; Westenbrink, E.W.; Rogers, C.; Vaughan, A.S.; Swingler, S.G. Aging of Biodegradable Oils and Assessment of their Suitability for High Voltage Applications. IEEE Trans. Dielectr. Electr. Insul. 2011, 18, 728-738. [CrossRef]

17. Hegemann, G. PCB-Problematik und Midel 7131-Eine umweltfreundliche Isolierflüssigkeit. Chem. Ztg. 1986, 110, 67-72.

18. M\&I Materials. Safety Data Sheet Midel 7131; M\&I Materials: Manchester, UK, 2012.

19. Liebschner, M. Interaktion von Ölspalten und Fester Isolation in HVDC-Barrierensystemen; Fortschritt-Berichte VDI-Verlag: Düsseldorf, Germany, 2009.

20. Rumpelt, P.; Jenau, F. Investigation on DC conductivity of alternative insulating oils as an application for HVDC converter transformers. In Proceedings of the 19th International Conference on Dielectric Liquids (ICDL), Manchester, UK, 25-29 June 2017.

21. Aakre, T.G.; Ve, T.A.; Hestad, Ø.L. Conductivity and permittivity of midel 7131: Effect of temperature, moisture content, hydrostatic pressure and electric field. IEEE Trans. Dielectr. Electr. Insul. 2016, 23, 2957-2964. [CrossRef]

22. Suh, Y.K. Modeling and Simulation of Ion Transport in Dielectric Liquids-Fundamentals and Review. IEEE Trans. Dielectr. Electr. Insul. 2012, 19, 831-858.

23. Vahidi, F.; Haegele, S.; Tenbohlen, S.; Rapp, K.; Sbravati, A. Study on Moisture Influence on Electrical Conductivity of Natural Ester Fluid and Mineral Oil. In Proceedings of the Electrical Insulation Conference, Baltimore, MD, USA, 11-14 June 2017.

24. Schober, F. Dielectric behaviour of HVDC insulating materials, polarization and conduction processes in mineral oil and in pressboard impregnated with different fluids. In Proceedings of the 19th International Symposium on High Voltage Engineering (ISH 2015), Pilsen, Czech Republic, 23-28 August 2015.

25. Schober, F. Elektrische Leitfähigkeit und Dielektrisches Verhalten von Pressspan in HGÜ-Isoliersystemen. Available online: https:/ /d-nb.info/1095904108/34 (accessed on 14 December 2017).

26. Rumpelt, P.; Jenau, F. A study of oil impregnated pressboard insulation based on ester fluids for an application in HVDC insulation systems. In Proceedings of the International Conference on Environment and Electrical Engineering, Milan, Italy, 6-9 June 2017.

(C) 2017 by the authors. Licensee MDPI, Basel, Switzerland. This article is an open access article distributed under the terms and conditions of the Creative Commons Attribution (CC BY) license (http:/ / creativecommons.org/licenses/by/4.0/). 